\title{
Carbonate in soil: A theoretical consideration on, and proposal for its fabric analysis. 1. Crystic, calcic and fibrous plasmic fabric
}

\section{Bal}

Soils Department of the State University Utrecht, Section Micropedology, Sorbonnelaan 4, Utrecht, the Netherlands

Accepted: 1 October 1974

\section{Summary}

The way of occurrence (fabric) of carbonate in 7 different soils was studied to make a proposal for its fabric analysis. These soils, developed in calcareous loess and marine deposits, are located in Afghanistan, the USSR, Germany and the Netherlands.

In this first instalment of this study the simple plasmic fabrics crystic, calcic and fibrous are defined. Their distinction is primarily based on theoretical considerations of Brewer's concepts (Brewer, 1964); moreover, they are readily applicable.

Apart from fabric descriptions, attention is paid to the formation of these fabrics.

In the second instalment of this study (Bal, 1975), K-fabric, carbonate crystal tubes, and intercalary carbonate crystals will be discussed.

\section{Introduction}

Studies on fabrics of carbonate in soil are of very great importance for studies on soil genesis (Brewer, 1964; Blokhuis et al., 1968-1969; Mulders, 1969; Siderius, 1973; Buursink \& Bal, 1975). Knowledge of these fabrics (e.g. the carbonate being finely dispersed, or accumulated in nodules, etc.) may also be useful for agriculture, because they may be correlated with several soil chemical reactions (i.e. chemical soil fertility). It is therefore considered inadequate to determine carbonate merely as a percentage of weight as is usually done in agriculture.

In the literature the fabrics of carbonate in soil are described in various ways, especially when the carbonate occurs more or less dispersed (e.g. Gile et al., 1965; Mulders, 1969; Kowalinski et al., 1972; Sehgal et al., 1972). This is probably because Brewer (1964) in his valuable book 'Fabric and mineral analysis of soils' described individual carbonate crystals only when these occur in crystic plasmic fabric (i.e. the crystals are arranged very close together: Fig. 1), and as intercalary crystals (i.e. single large crystals set in the soil material at rather large mutual distance as compared to the arrangement of crystals in a crystic plasmic fabric (Bal, 
1975, Fig. 7). Unfortunately he omitted to explain how to describe carbonate occurring in patterns different from those mentioned above, e.g. more or less dispersed as fine grains in the soil material (Fig. 3), or as single crystal needles, or many of such needles forming a mat as it were (Fig. 8-10).

This lack in Brewer's proposal might possibly also explain the description of carbonate as plasma by one group of authors (e.g. Brewer, 1964; Mulders, 1969), whereas other authors consider it skeleton grains (e.g. Kowalinski et al., 1972).

For the above-mentioned reasons the author thought it useful to explain a philosophy on the way in which one can consider carbonate in soil to allow its efficient micromorphological description, i.e. resulting in a proposal for some fabrics. This philosophy is essentially based on Brewer's (1964) concepts.

Apart from the proposal for these fabrics attention will be paid to their genesis.

Seven soils formed in calcareous parent materials and occurring in Asia and Europe were studied. Four of these soils have been formed in calcareaus loess, these are: a Calcixerollic Xerochrept ${ }^{1}$ (Serozem) in Afghanistan (Buursink \& Bal, 1975); a Pachic Vermustoll (typical, deep, fertile Chernozem formed in loessial loam) in the USSR (monolith SU 6 of the International Soil Museum, Utrecht); a Haplic Vermustoll (?) ('Dunkelbrauner Rheintal Tschernosem' with powdery lime (pseudo mycelium) between $30-60 \mathrm{~cm}$ in the A horizon) in Germany; and a Typic Hapludalf in the Netherlands. The fifth soil is an Entic Vermudoll formed in a sandy loam sediment of the former Zuider Zee (Netherlands), whereas the last two soils are a Hydraquent and a Haplaquent, respectively, formed in marine deposits (Salt marsh and Tidal flat) in the Netherlands.

\section{Discussion}

\section{Are calcite crystals skeleton grains or accumulations of plasma?}

According to Brewer (1964, pp. 12 and 303), soil materials are essentially composed of two groups of constituents, i.e. plasma and skeleton grains. The difference between these groups is based on the difference in capability of being moved, reorganized and/or concentrated by the (non-drastic) processes of soil formation. Plasma comprises the relatively unstable constituents, whereas skeleton grains are relatively stable.

Plasma includes two types of materials, i.e.:

1. all soil particles smaller than $2 \mu \mathrm{m}$ (e.g. clay minerals, fragments of quartz grains, etc.), which are the plasma grains;

2. readily and rather soluble materials, which may accumulate into particles smaller than $2 \mu \mathrm{m}$, but also into large amorphous, or crystalline bodies (e.g. chalcedony, sesquioxides, humic acids, etc.).

Skeleton grains, on the contrary, are always relatively stable individual grains larger than $2 \mu \mathrm{m}$.

1 The names of the soils in italics represent the soils' classification according to the Soil Survey Staff (Anon., 1967, 1970).

Neth. J. agric. Sci. 23 (1975) 
Literature studies reveal that calcite crystals are assumed to be skeleton grains if they are inherited from the parent rock. This is very clearly expressed by Sehgal et al. (1972), whilst one would arrive at the same conclusion from the description of skeleton grains composed of calcite by Kowalinski et al. (1972). Gile et al. (1965) explain how allogenic carbonate grains tend to act as skeletal material. This is, to some extent, understandable for soils in which single grains, or small clusters of these are present in great quantities throughout the soil, e.g. as in the Xerochrept in Afghanistan (Buursink \& Bal, 1975).

From the foregoing one could draw the conclusion that, on the contrary, skeleton grain-sized accumulations of $\mathrm{CaCO}_{3}$ formed in situ (Bal, 1975, Fig. 1-4) are not considered skeleton grains, but particular configurations of plasma. Usually these are considered configurations of plasma indeed.

Although the classification of calcite grains as skeleton grains is, to a certain extent, understandable when they occur in large amounts throughout the soil, it is not clear why primary grains just by virtue of being primary should be classified as skeleton grains. In the same way of reasoning one could consider clay minerals in a clay sediment, or inherited sesquioxidic nodules in a colluvium as skeleton grains because these are primary." This is, however, without any sense. In this respect the question rises how the coarse calcite grains in an inherited (primary) carbonate glaebule would be described by Sehgal et al. (1972) and Kowalinski et al. (1972). Although the glaebule is primary, the calcite grains need not necessarily to be considered skeleton grains.

According to Brewer's definitions (Brewer, 1964, pp. 12 and 303) such (skeleton grain-sized) grains of $\mathrm{CaCO}_{3}$ are accumulations of plasma, because the calcium carbonate is a rather soluble constituent whether it is primary or secondary. Thus, also calcium carbonate shells (biorelicts according to Blokhuis et al., 1968-1969), and fragments of limestone in the soil are composed of plasma.

Many of these carbonate biorelicts can be observed in the Dutch soils formed in the marine sediments; to a lesser extent or not at all in the other soils studied. Moreover, their recrystallization in the soil may be observed.

In the same way and inherited pedological feature composed of clay minerals, which are smaller than $2 \mu \mathrm{m}$, is regarded as being composed of plasma.

Brewer based the difference between plasma and skeleton grains principally on genetic interpretations (i.e. the difference in capability of these materials of being moved, reorganized and/or concentrated by the processes of soil formation; see Bal, 1973, pp. 17-18). The introduction of an additional uncertainty (i.e. the origin of the material) in the decision whether a particular constituent is plasma or not should be avoided. This opinion is also based on research carried out by Parfenova et al. (1965) and Buursink \& Bal (1975), which have amply explained that it is often hardly possible to establish with certainty whether calcite grains arranged throughout the soil are allogenic or authigenic.

2 In this context 'primary' means that the soil material has not been formed on the spot, or in the soil where it occurs. 


\section{Carbonate plasmic fabrics}

In the soil the carbonate plasma may occur intimitely mixed with other plasma throughout the soil, but it may also occur accumulated in pedological features such as nodules, or crystallaria. ${ }^{3}$

In the organization of soil materials as proposed by Brewer (1964) and Bal (1973) one can study, for example, the distribution of these carbonate pedological features which represents a certain level in the organization. However, one can also study the fabric of the carbonate plasma within such carbonate pedological features, or generally within calcareous soil materials. For example, carbonate plasma may occur as closely assembled large crystals, but also as rather widely scattered very fine crystals throughout the soil material. The spatial arrangement (fabric) of the plasma itself is named plasmic fabric (Brewer, 1964, p. 155); in the organization mentioned it represents another (lower) level.

Fig. 1. Fine crystic plasmic fabric in a large carbonate nodule in the Calcixerollic Xerochrept (Serozem). Note the presence of an embedded, small carbonate nodule in the middle of the top side of the photograph. Thin section under crossed polarizers. $\times 138$,

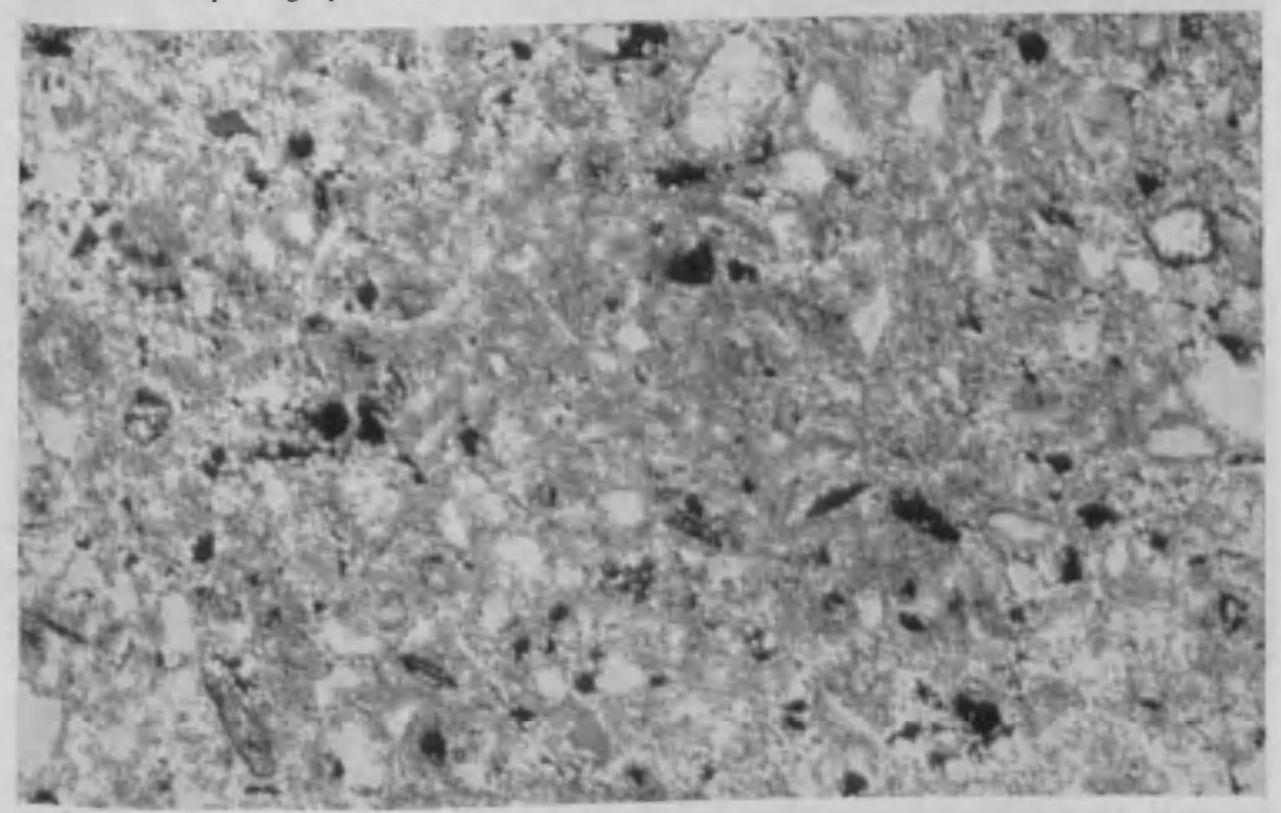

${ }^{3}$ The definition of pedological features after Brewer $(1964$, p. 142) was redefined by the author (Bal, 1973, p. 41) as: Pedological features are bodies, which often occur as recognizable units within a soil material. In such cases they are distinguishable from the enclosing material for any reason, such as origin (deposition as an entity), differences in degree of accumulation of some fraction of the plasma, or differences in arrangement of the constituents (fabric).'

Examples of carbonate crystallaria will be discussed in part 11 of this study in the sections 'Carbonate crystal tubes' and 'Intercalary calcite crystals' (Bal, 1975).

Neth. J. agric. Sci. 23 (1975) 


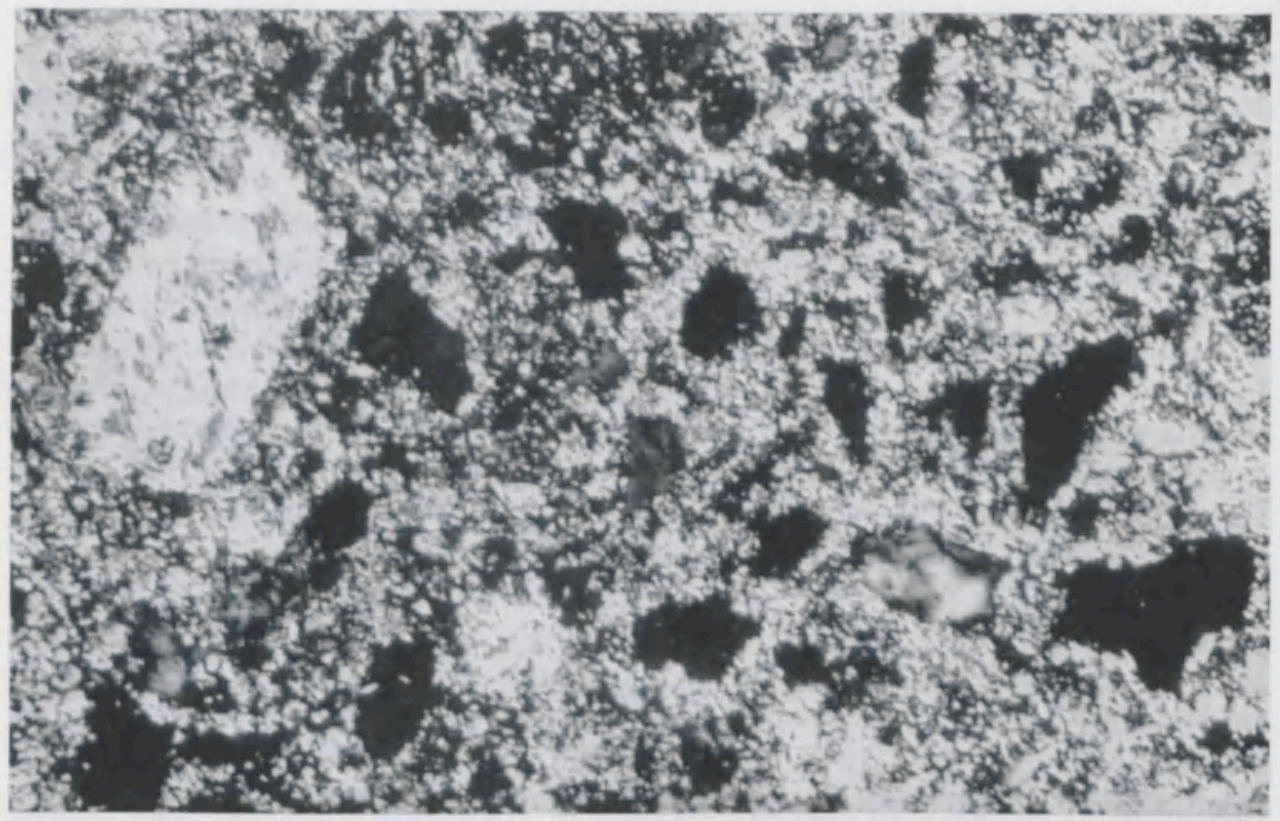

Fig. 2. Fine crystic plasmic fabric (grading into dense calcic plasmic fabric) in a carbonate nodule in the Calcixerollic Xerochrept (Serozem). An embedded, elongated intercalary carbonate crystal is visible on the left side of the photograph. Thin section under crossed polarizers. $\times 330$.

Carbonate in soil may occur in several plasmic fabrics. These will be discussed and distinguished as crystic, calcic and fibrous plasmic fabric, respectively.

Crystic plasmic fabric. Brewer (1964, pp. 317-318) used the term crystic to describe soil materials almost completely composed of a dense mass of crystals. The space between the crystals is absent or almost absent (Brewer, 1964, Fig. 113 and 114). The crystals may be small (forming fine crystic plasmic fabric), but also large (forming coarse crystic plasmic fabric). Carbonate nodules and neo-cutans are often fine-grained (Fig. 1 and 4). Several crystal tubes, on the contrary, are often coarse-grained (Bal, 1975, Fig. 1, 2 and 3). Moreover, coarse carbonate crystals may be embedded in a fine crystic plasmic fabric, as found in some carbonate nodules (Fig. 2; Bal, 1975, Fig. 4).

Several crystic plasmic fabrics can be distinguished on the arrangements of their crystals. Only one of these will be described in the section 'carbonate crystal tubes' of Part 2 of this study (Bal, 1975).

Calcic plasmic fabric. No specific term does yet exist to describe the fabric of plasma in which small calcite grains occur that determine to a great extent its optical behaviour (Fig. 3 and 5). However, such a specific term is warrantable because this fabric possibly occurs in many soils. It was observed in all the soils studied. 


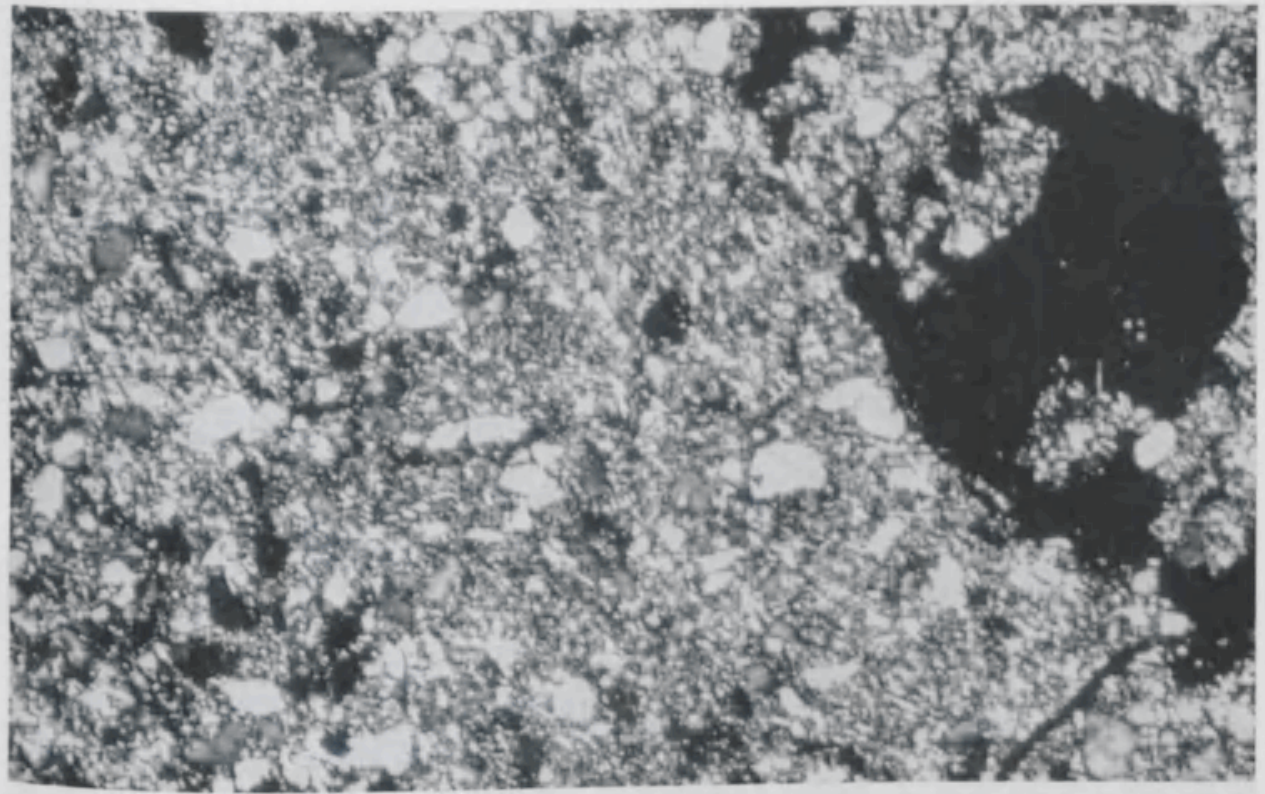

Fig. 3. Calcilo-silasepic plasmic fabric in the $\mathrm{C}$ horizon of the Pachic Vermustoll (Chernozem). Most of the small, isolated, anisotropic islands occurring throughout the soil material are carbonate grains of at most $10 \mu \mathrm{m}$ in size. Thin section under crossed polarizers. $\times 144$.

Fig. 4. Channel neocalcitan with fine crystic plasmic fabric, which grades into calcit ${ }^{10}$-silasepic plasmic fabric of the surrounding s-matrix. Thin section from the Pachic Vermustoll (Chernozem). Crossed polarizers. $\times 136$.

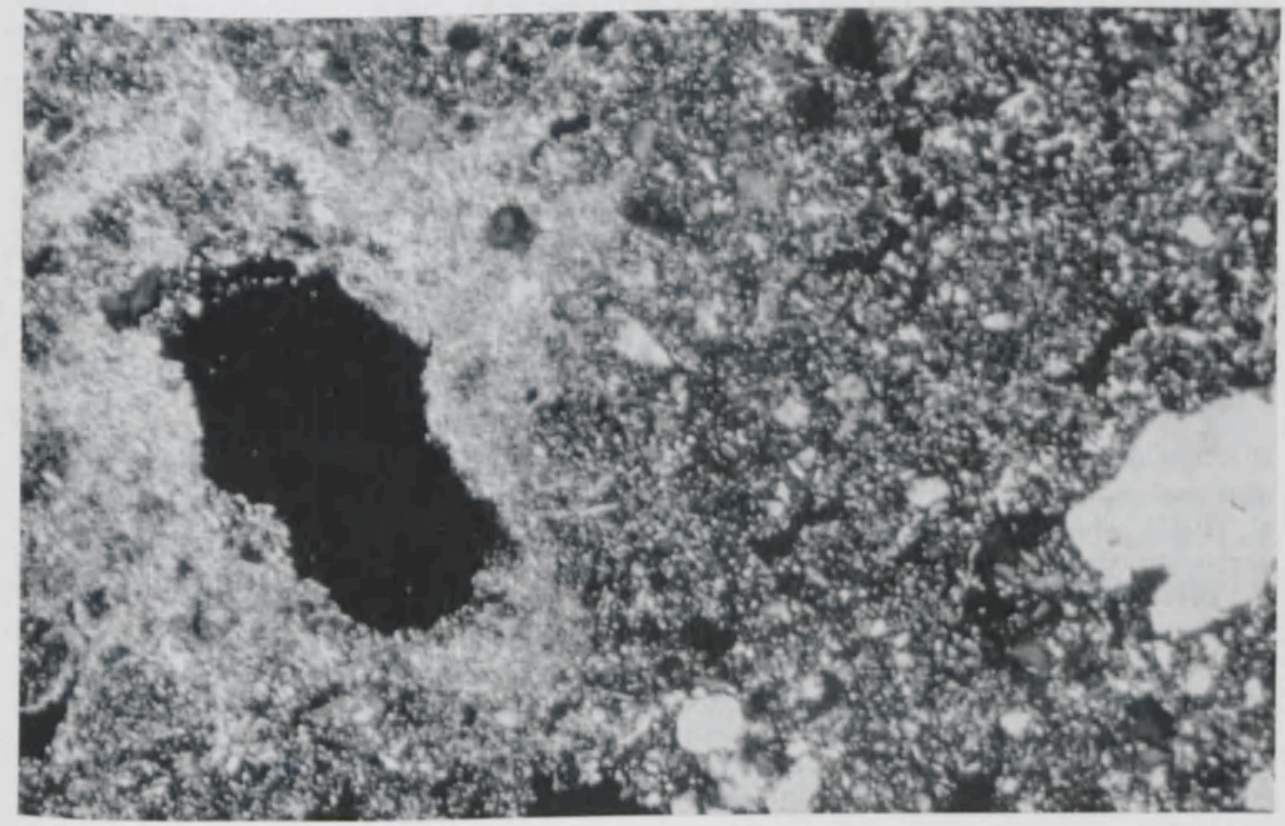




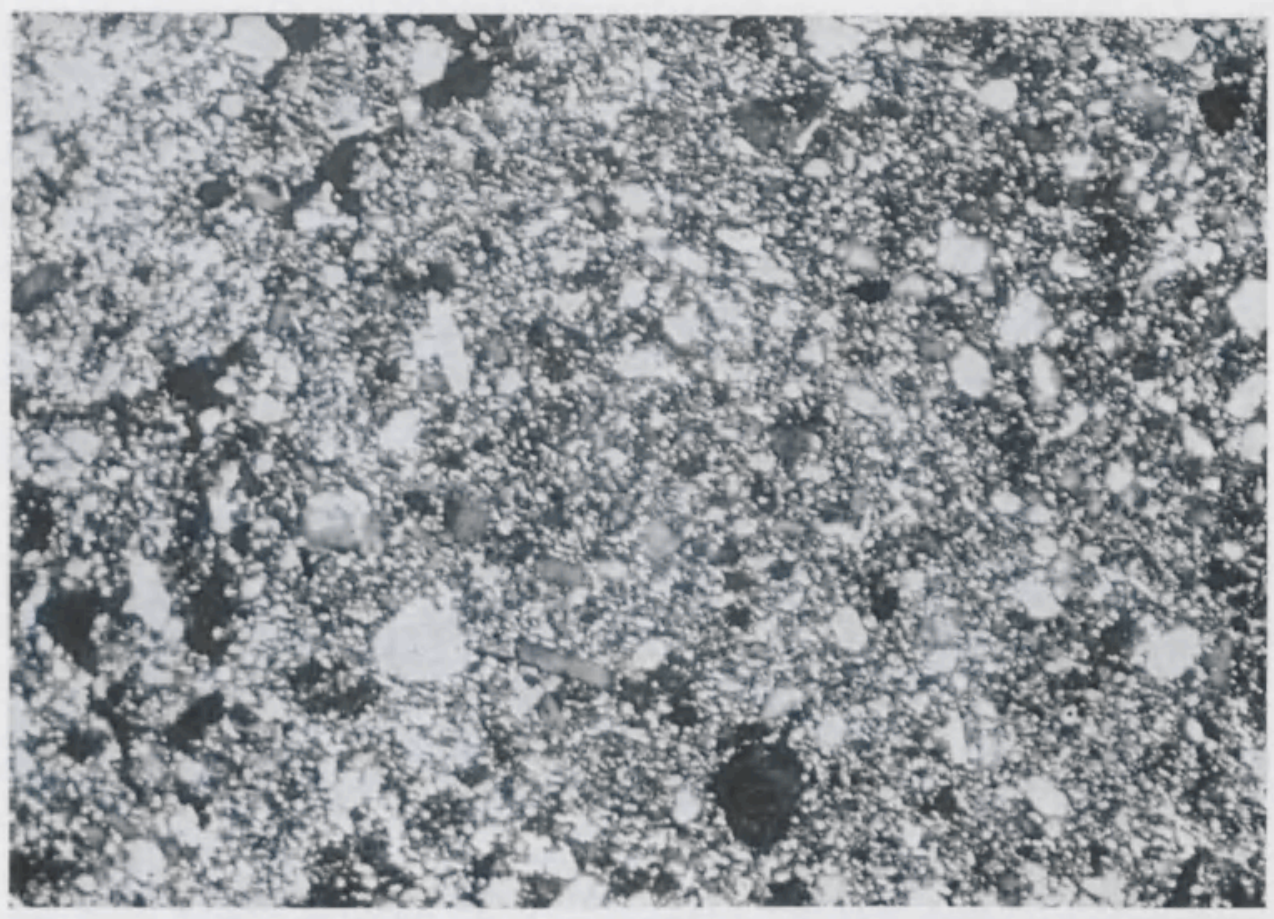

Fig. 5. Calcit ${ }^{10}$-silasepic plasmic fabric, and a porphyroskelic basic fabric in the $\mathrm{C}$ horizon of the Pachic Vermustoll (Chernozem). Thin section under crossed polarizers. $\times 117$.

Moreover, the need for uniformity to describe such a fabric appears from previous attempts listed below.

1. Often Brewer's term 'crystic' is used, for instance by Kowalinski et al. (1972). But, from the foregoing section it is questionable whether Brewer would describe such a fabric as crystic.

2. Sehgal et al. (1972) used Kubiena's (1938) somewhat cumbersome terminology 'microcrystalline interflorescences' to describe the presence of such calcite crystals. 3. Mulders (1969, p. 164) introduced the term 'calciasepic' for the fabric of plasma which exhibits a flecked orientation and which has an important proportion of carbonates, for instance $15-40 \%$.

It is not quite clear whether Mulders has in mind percentage by weight or by volume. It is also unclear why he used the $15-40 \%$ limit. It is thought, however, that the refers to Gile et al. (1965), who state that a minimum ranging from about $15-40 \%$ by weight of authigenic carbonate $\left(\mathrm{CaCO}_{3}\right.$ equivalent calculated as percentage of fine earth material) is required for the development of K-fabric (see Bal, 1975).

In my opinion one should, for fabric studies, express the carbonate content as percentage by volume, as is also proposed by Gile et al. (1965) for the distinction of different K horizons. Moreover, this percentage should not be too high (for calcic fabric) as in that case the fabric becomes crystic.

Mulders used the denomination calci only in combination with asepic plasmic 
fabric. However, the spatial arrangement of such small-sized accumulations of $\mathrm{CaCO}_{3}$ can be considered to represent a separate plasmic fabric. Moreover, the use of the prefix calci introduced by Mulders is not quite clear and can give rise to misunderstanding. This is in fact due to the difficulty that pedological features are not always described separately, which will be discussed below.

All soil materials smaller than $2 \mu \mathrm{m}$ are regarded as plasma; if larger they are skeleton grains, peds, or pedological features (Brewer, 1964). In this context an accumulation of $\mathrm{CaCO}_{3}$ larger than $2 \mu \mathrm{m}$ (e.g. $\left.10 \mu \mathrm{m}\right)$ is a pedological feature.'

Thus, strictly speaking, small-sized single carbonate crystals (or clusters of these crystals) of, say, $2-10 \mu \mathrm{m}$ are pedological features. However, it is questionable whether it makes sense to describe these small accumulations of $\mathrm{CaCO}_{3}$, which occur close to each other throughout the s-matrix without forming a crystic fabric, in a way as is usually done with pedological features. For practical reasons it is thought to be acceptable to describe these small-sized accumulations in that particular distribution pattern as part of the s-matrix.

The same idea might have occurred to Mulders (1969) when he introduced the term calciasepic. However, this is thought unlikely, because Mulders did not describe calcite crystals of $2-10 \mu \mathrm{m}$ as pedological features, but as plasma grains. Therefore, it is more likely that he has considered calciasepic fabric on the analogy of the silasepic plasmic fabric described by Brewer (1964, p. 310); a fabric in which anisotropic plasma domains are difficult to recognize because of the presence of high proportions of silt-sized skeleton grains.

In a similar way Brewer $(1964$, p. 302$)$ regards plasma separations as part of the $\mathrm{s}$-matrix since these are simply variations in arrangement. Plasma separations are in fact pedological features, but they are not described as such. On the contrary, they are considered part of the plasma of the s-matrix and described as occurring in the sepic plasmic fabrics (Brewer, 1964, pp. 311-316). These separations are recognizable as anisotropic domains with various patterns of preferred orientation; that is, plasma separations with a striated extinction pattern are present (Brewer, 1964, p. 311).

However, are such striations of anisotropic domains in the s-matrix always plasma separations? For example, in fabrics which are morphologically identical to masepic and mosepic and sometimes even omnisepic plasmic fabric these striations can be caused by deformation of units, which have been formed by illuviation of clay plasma (Jongerius, 1970; Buursink, 1971, p. 201; Fedoroff, 1972; Siderius, 1973 , p. 133). Skelsepic plasmic fabric can be formed by plasma separation, but also by weathering of minerals (Mermut et al., 1971; Siderius, 1973, p. 130). And although these striations are not plasma separations sensu stricto the fabrics in which they occur are described as sepic plasmic fabrics by the authors quoted. These examples illustrate that 'plasma separations' in plasmic fabrics can in fact be $\alpha$ - or $\beta$-accumulations (Bal, 1973, p. 43) ${ }^{5}$, or plasma concentrations (Brewer, 1964, p. 143).

- It should be realized in this relation that many pedological features are of small dimensions.

5 ' $\alpha$-accumulation is an accumulation of a constituent, or constituents formed by generation.'

' $\beta$-accumulation is an accumulation formed by transportation of one, or more, existing constituents.' 
The concept of s-matrix according to Brewer (1964, p. 147) does not allow for the description of plasma accumulations as part of the s-matrix, because only plasma separations are regarded as being part of the s-matrix. Description of plasmic fabrics according to Brewer therefore requires knowledge on the genesis of particular clayey pedological features. Unfortunately the genesis of such features is not always known.

Apart from the above-mentioned risk of wrongly interpreting striations of anisotropic domains as plasma separations, it is conceivable that Brewer described particular pedological features as part of the s-matrix for practical reasons. In a philosophy on a spatial organization of soil materials one might consider such striations of anisotropic domains in the s-matrix always as part of this, irrespective of their genesis, because their genesis is not always known. This genesis could be interpreted separately; moreover, with progressing knowledge on the genesis of these fabrics it is not excluded that one can distinguish several subfabrics on a genetic basis. However, at the present stage of knowledge one could, for convenience sake, always describe these fabrics as if they were sepic fabrics. On the other hand it is understandable that then one may have objections to denominations which end on sepic (e.g. masepic, omnisepic, etc.), because these have a genetic bearing.

The question whether or not striations of anisotropic domains, and small accumulations of carbonate in the s-matrix must be considered part of the s-matrix, may also hold for striations of organic plasma in the s-matrix (discussed earlier; Bal, 1973, p. 70).

However, apart from the theoretical problems on several small-sized pedological features in the s-matrix discussed above, it may be wondered whether describing all pedological features separately makes sense at all. For, if all of these would be described separately, description of soil materials would most probably not be feasible. For the same reasons Bal (1973, pp. 43-44) did not give an account of every pedological feature in organic materials as such. That is why he prefers to characterize several pedological features of different type and often small size in combination with the s-matrix, notably when they are formed from, or are of the same composition as, (part of) the surrounding soil plasma as is the case in many calcareous soils.

The description of plasmic fabric then would involve:

- verification of the presence or absence of above-mentioned pedological features;

- if present, characterization of their spatial arrangement, e.g. masepic fabric.

In conclusion, it is proposed to use the name 'calcic' for that fabric of plasma in which the $\mathrm{CaCO}_{3}$ is present as single grains or clusters of grains smaller than approximately $10 \mu \mathrm{m}$ occurring close to each other throughout the s-matrix without forming a crystic plasmic fabric however (Fig. 3 and 5). The calcic plasmic fabric of course can grade into crystic plasmic fabric in case the space between the crystals is almost absent (Fig. 2 and 4; Bal, 1975, Fig. 4).

The size limit of $10 \mu \mathrm{m}$ is feasible for rather detailed descriptions. However, one can adapt this upper limit to the purpose of the description. Thus, for less detailed investigations one could fix it at $\chi \mu \mathrm{m}(\chi>10)$ when carbonate accumulations of 

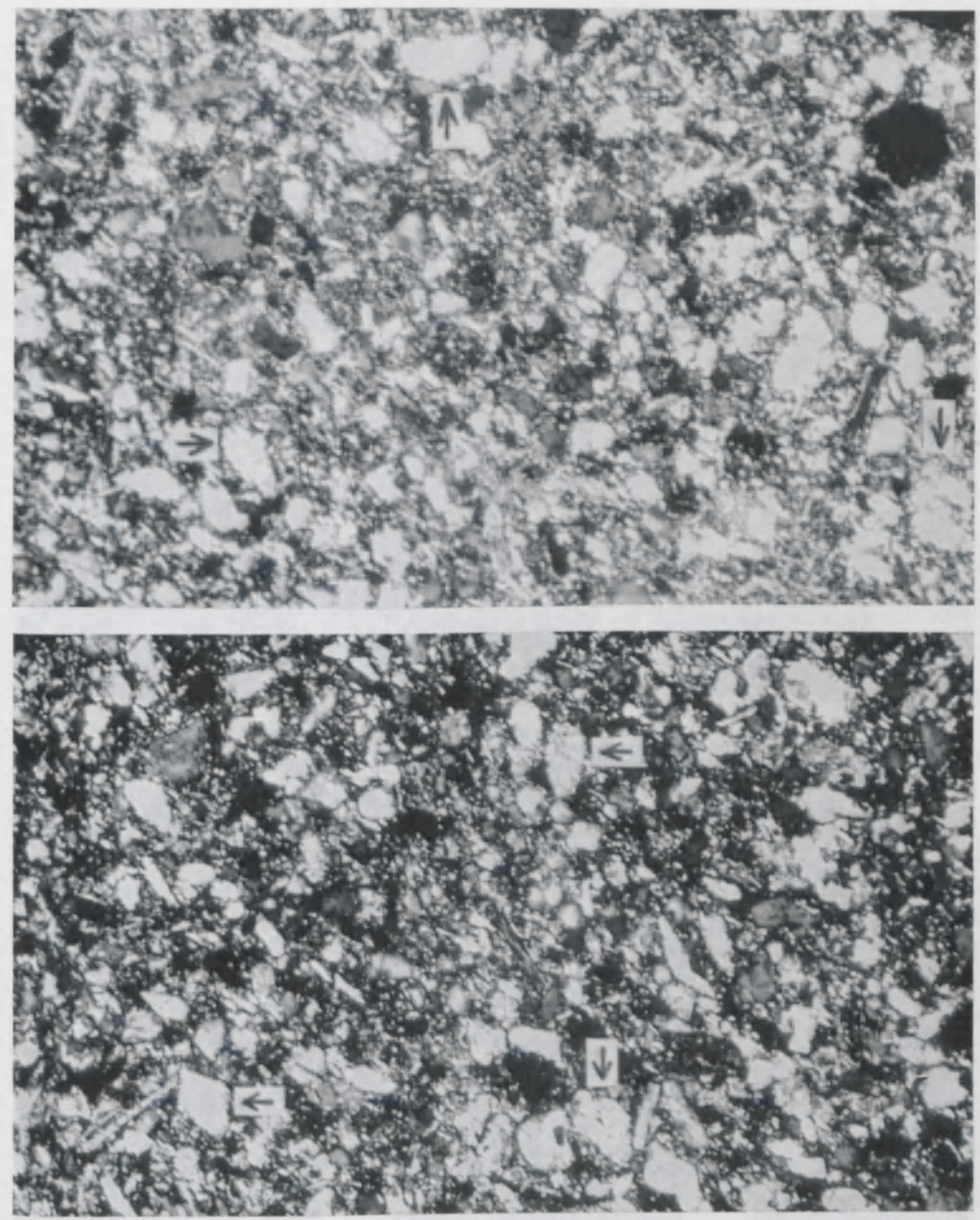

Fig. 6. Calci-asepic plasmic fabric in the Calcixerollic Xerochrept (Serozem). Most of the small, isolated, anisotropic islands occurring throughout the soil material are carbonate grains of at most $10-20 \mu \mathrm{m}$ in size. The others are silt-sized skeleton grains. The larger anisotropic islands are accumulations of carbonate of at most $100 \mathrm{\mu m}$ in size (some are indicated with an arrow) or skeleton grains. Thus, the plasmic fabric can be described as calci'00-silasepic, or as calci'10-silasepic. In the latter case the accumulations of carbonate larger than $10 \mu \mathrm{m}$ are described separately as pedological features. Details of this particular fabric are shown in Fig. 7. Thin section under crossed polarizers. $\times 138$ and $\times 128$. 

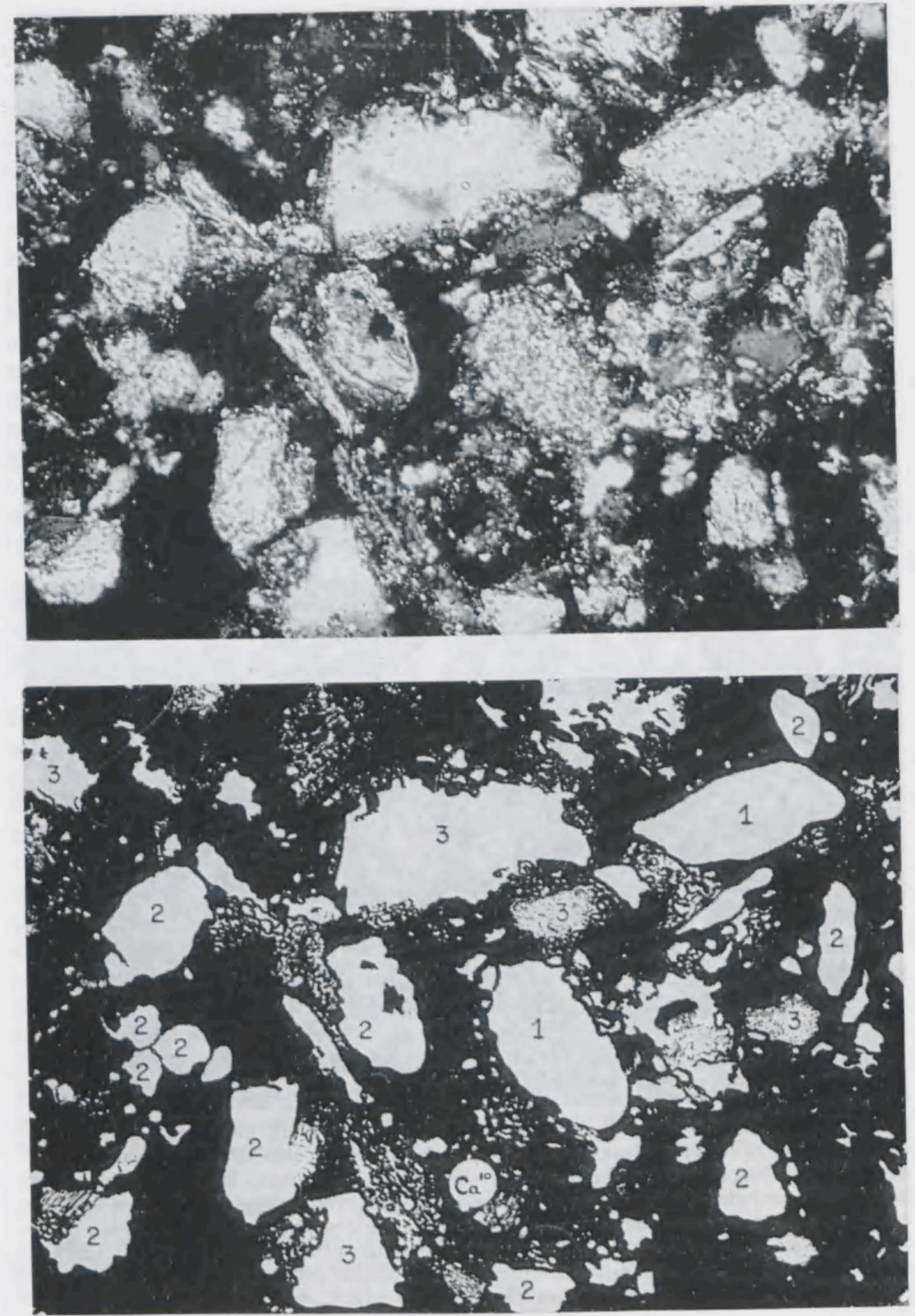
Fig. 7. Detail of the calci-asepic plasmic fabric in the Calcixerollic Xerochrept (Serozem) shown in Fig. 6.

$\mathrm{Ca}^{10}$ : Carbonate crystals or clusters of them, smaller than $10 \mu \mathrm{m}$.

1: Carbonate nodules larger than $10 \mu \mathrm{m}$ with fine crystic plasmic fabric; they are surrounded by $\mathrm{Ca}^{10}$.

2: Intercalary calcite crystals which may be surrounded by $\mathrm{Ca}^{10}$. Note that these crystals are more or less elongated.

3: Skeleton grains surrounded by $\mathrm{Ca}^{10}$.

Thin section under crossed polarizers. $\times 277$.

$\chi \mu \mathrm{m}$ occur close to each other and/or together with fine-grained carbonate throughout the soil material, e.g. as in the Xerochrept. However, to avoid confusion it is proposed to note down the $\chi$ together with the term calcic as calcic ${ }^{\chi}$. For example, if $\chi=100 \mu \mathrm{m}$ it is noted as calcic ${ }^{100}$ (Fig. 6). When the individual single crystals are large and the space between them is becoming large, and moreover fine-grained carbonate is becoming almost absent then calcic fabric grades into 'intercalary carbonate crystals' (see relevant section, Bal, 1975).

Fibrous plasmic fabric. The term fibrous is introduced here for describing distribution patterns of needle-shaped calcite (lublinite). As the needles are crystals we could in fact describe them as a type of crystic or calcic fabric, depending on their amount. However, for two reasons they are distinguished as being present in quite different fabrics, i.e.:

- the morphology and spatial arrangement of needle-shaped (acicular) crystals is quite different from those of other carbonate crystals;

- the term fibrous can also be used for the description of fabrics of other soil materials, because it is only a denomination of a spatial arrangement.

Within the fibrous carbonate plasmic fabric at least two different types of internal basic distribution patterns can be distinguished, i.e. banded and hyphantic. In the banded basic distribution pattern the calcite needles are arranged more or less parallel forming a bundle (Fig. 8 and 9). In the hyphantic basic distribution pattern the calcite needles are arranged in such a way that they form a woven pattern, in which the arrangement of the crystals may sometimes even be rectangular (Fig. 10)."

B The term 'banded' for a basic distribution pattern is adopted from Brewer (1964, p. 168). Although the term 'banded' is very suitable for a type of basic distribution pattern I would prefer the term parallel for this particular arrangement of the calcite needles. This is because the term 'banded' creates the impression of the occurrence of groups of like materials in bands. For example, in a fluvial sediment the sand and clay may occur in thin alternating layers, or in other words the sand and clay occur banded. Applied in this context the term 'banded' does not give information on the internal fabric of the bands, e.g. in a band composed of needleshaped carbonate these needles may be arranged parallel, but also hyphantic. However, Brewer (1964, p. 169) proposed the term parallel already for describing a referred distribution pattern. To avoid confusion the present author accepted therefore the term banded.

The name hyphantic is adopted from a similar basic distribution pattern in which organic skeleton grains may occur as described by Bal (1973, pp. 92-93). It is coined from the Greek word hyphantos (= woven). 


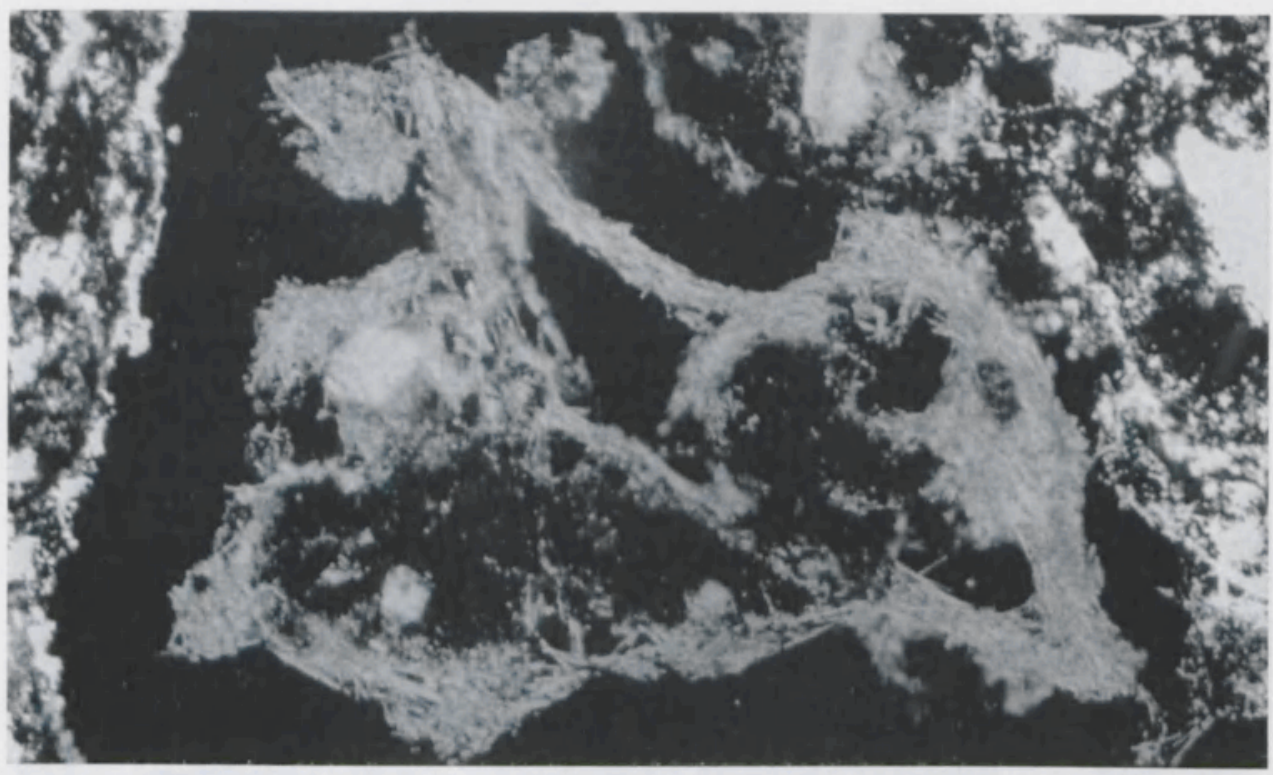

Fig. 8. Fibrous plasmic fabric (with mainly a banded internal basic distribution pattern) in calcitans, which are, in this case, developing into a crystallarium. Thin section from $30.45 \mathrm{~cm}$ in the A horizon of the Haplic Vermustoll (Tschernosem). Crossed polarizers. $\times 190$.

Fig. 9. Vugh calcitans with a banded fibrous plasmic fabric at $30-45 \mathrm{~cm}$ in the Haplic Vermustoll (Tschernosem). The opposite cutans are interconnected by a bridge, which may be interpreted as an initial stage in the formation of a crystallarium, or of a nodule with fine crystic plasmic fabric as shown in Fig. 10. Thin section under crossed polarizers. $\times 195$.

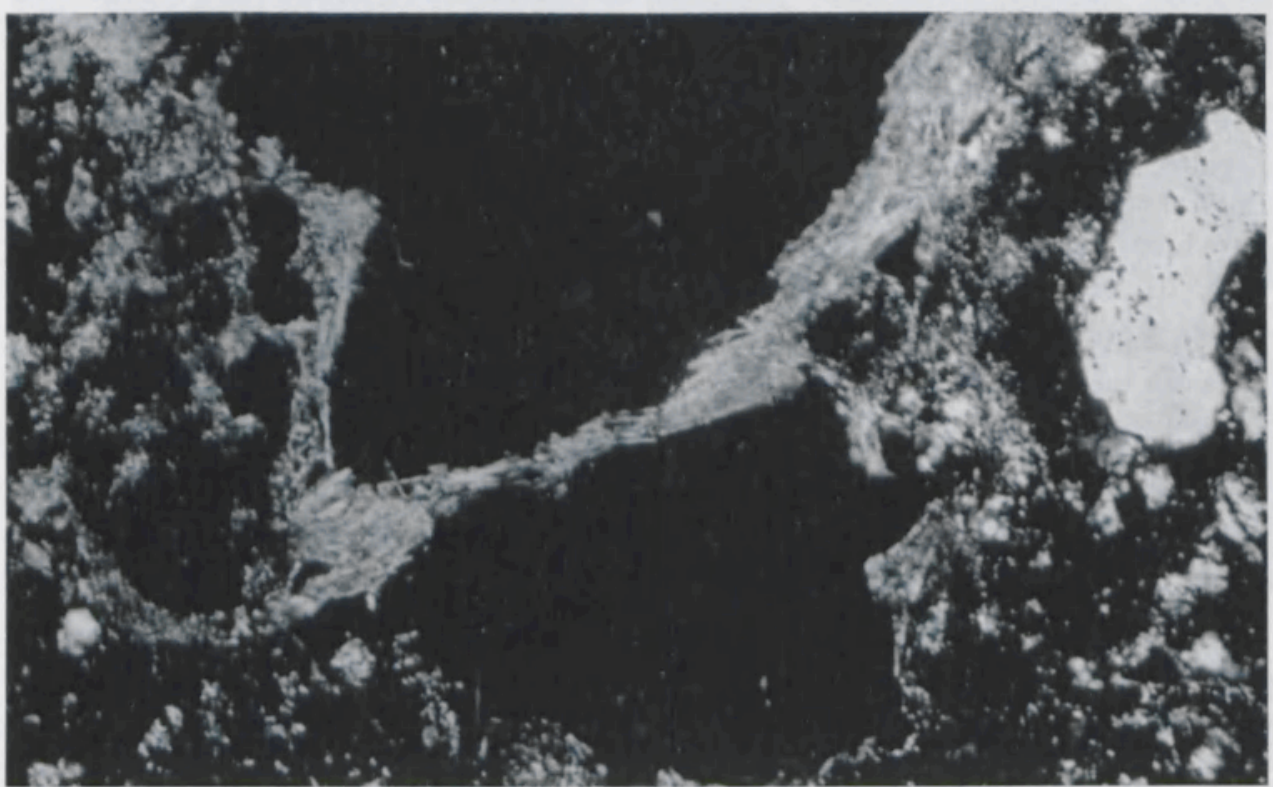




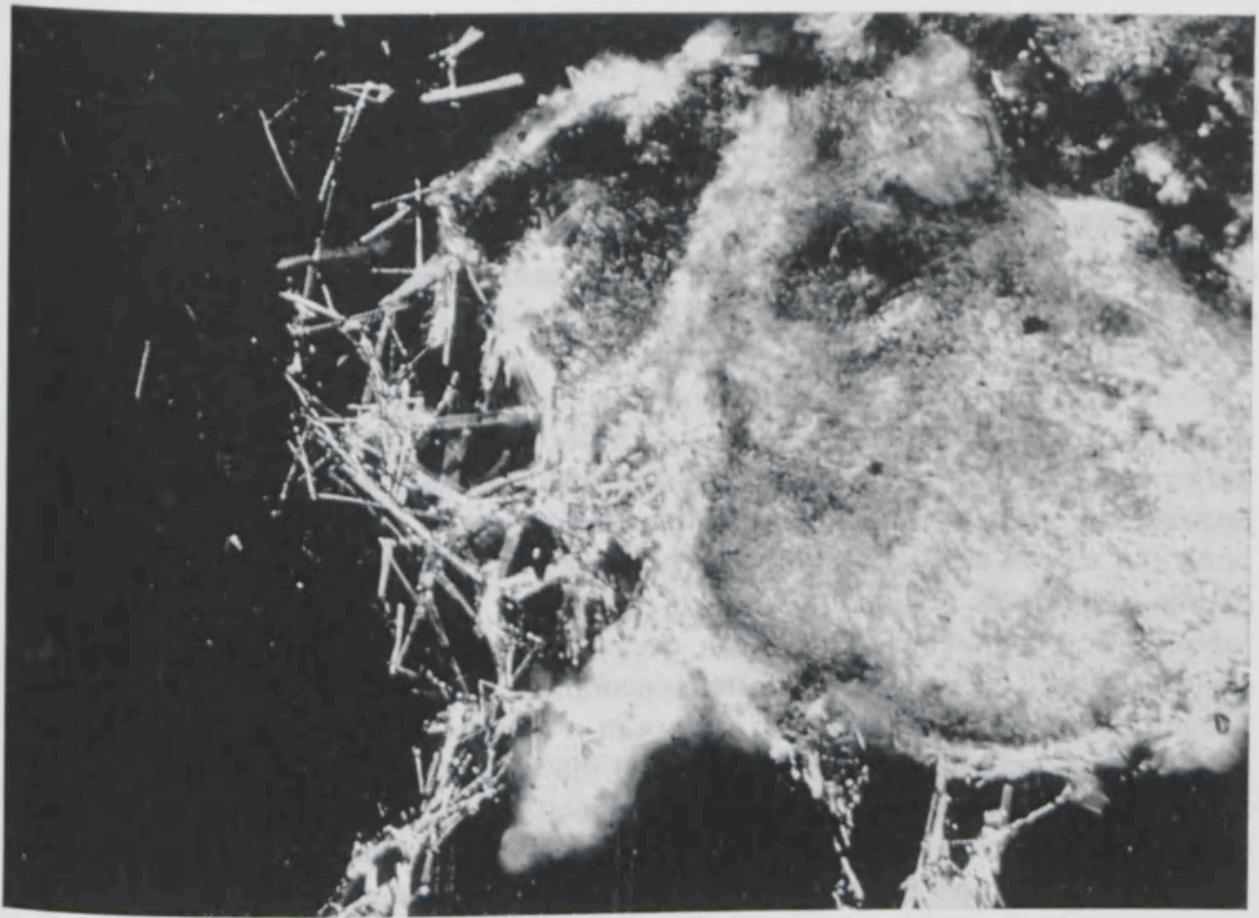

Fig. 10. Carbonate nodule (right on Figure) coated by a calcitan. Note that:

1. The calcitan has a fibrous plasmic fabric with a hyphantic internal basic distribution puttern (especially left on Figure).

2. The nodule has been formed from a $\beta$-accumulation of lublinite. Its plasmic fabric is an intergrade between fibrous and fine crystic; the nodule is thought to be in a relatively young stage of formation.

Thin section from $30-45 \mathrm{~cm}$ in the A horizon of the Haplic Vermustoll (Tschernosem) Crossed polarizers. $\times 340$.

Final consideration; simple and compound plasmic fabrics. The way of describing carbonate explained above is understandable and readily applicable. The philosophy on which these fabrics are based is slightly different from Brewer's concept on plasmic fabrics, especially with respect to the calcic fabric. This is because the carbonate crystals larger than $2 \mu \mathrm{m}$ in this fabric are principally pedological features similar to intercalary carbonate crystals. Thus, in fact the calcic fabric is a spatial arrangement of particular carbonate pedological features.

This implies that calcic fabric might be regarded as an intergrade between crystic plasmic fabric and intercalary carbonate crystals. In order to be consistent with the philosophy of Brewer, calcic fabric is considered a plasmic fabric. For, considering the plasmic fabrics described by Brewer (1964) one arrives at the conclusion that many of these fabrics (especially the sepic fabrics) are in fact descriptions of spatial arrangements of particular pedological features. According to 
Brewer, however, it is only when these pedological features are plasma separations that they may be regarded as part of the s-matrix (Brewer, 1964). This implies that one must know the genesis of these pedological features, which is, however, not always possible.

On the other hand striations of anisotropic domains in the s-matrix which are not formed by separation, but by some other process (e.g. illuviation) are often described in the literature as if they were plasma separations. Theoretically this cannot be justified, although for practical reasons it is understandable that several pedological features are not described separately, but as part of the s-matrix.

From the above-mentioned it is obvious that the calcic fabric could be considered a basic distribution pattern of carbonate crystals, but also a spatial arrangement of small-sized carbonate pedological features. In both cases it may be justified to consider these fabrics plasmic fabrics.

As the calcic, crystic, and fibrous plasmic fabrics are essentially arrangements of like individuals in relation to each other, they can be distinguished as simple fabrics. Moreover, calcic fabric can occur combined with other fabrics, such as sepic fabrics. Calcic fabric is often encountered in combination with silasepic plasmic fabric; in other words it occurs in a compound fabric. In such cases the name of the compound fabric begins with the indication of the carbonate plasmic fabric by the prefix calci- (for example calci-silasepic plasmic fabric (Fig. 3, 5 and 6)), thus, not calcic!

Where crystic and fibrous are morphological denominations, calcic is in fact a name of the chemical composition. The author is fully aware of the need for an exact morphological denomination to define the fabric which is now named calcic.

Although it needs no argument that it is necessary and often easy to distinguish the carbonate plasmic fabrics from the plasmic fabrics in the system proposed by Brewer (1964, pp. 302-315) it is worthwhile to mention some similarities between them, i.e.:

- The calcic' $10(-20)$ plasmic fabric is more or less comparable with the 'insepic', or 'silasepic' fabric (Fig. 3 and 5).

- The calcic ${ }^{50}(-100)$ plasmic fabric may be compared with the 'insepic' to 'mosepic' plasmic fabric (Fig. 6).

- The crystic carbonate plasmic fabric (and especially the fine crystic) is more or less comparable with the 'omnisepic' plasmic fabric (Fig. 1).

- Another similarity presents itself in Fig. 4, in which the $\beta$-accumulation of carbonate around the channel will be described as a neo-calcitan with fine crystic fabric, whereas the surrounding s-matrix is characterized by calcic ${ }^{10}$ plasmic fabric. If the carbonate grains would be striations of anisotropic domains of clay minerals the fabric would be described as 'vo-insepic' plasmic fabric, or possibly as a neo-argillan and a s-matrix with 'insepic' plasmic fabric.

Occurrence and interpretation of crystic, calcic and fibrous plasmic fabrics in calcareous soil materials. Crystic plasmic fabrics may be authigenic as well as allogenic. The determination of their origin is often difficult. However, sometimes they can be recognized as authigenic, for example in carbonate crystal tubes, or in carbonate nodules with a diffuse boundary, or in (neo-)cutans. In other cases crystic plasmic fabrics can be recognized as allogenic, for example in fragments of oolithic limestone, which can occur in the soil as lithorelicts.

Calcic plasmic fabrics may be inherited from the parent material in view of 
their occurrence in the Entisols. It is not impossible that they are also authigenic.

Calcite in a fibrous fabric would only be preserved in xeromorphic soils (Kowalinski et al., 1972; Buursink \& Bal, 1975). It mostly occurs in cutans and even in crystallaria, or in an intergrade between these (Fig. 8 and 9). It may also be characteristic for soft carbonate glaebules, which are in an initial stage of their formation (see the Xerochrept in Afghanistan described by Buursink \& Bal, 1975). In the German Chernozem and the Afghan Xerochrept the author observed that densely packed fibrous fabric easily changes into fine crystic plasmic fabric (Fig. 10). Excrements may be enveloped and/or impregnated by lublinite; they may even be linked with each other by bridges of calcite in a fibrous fabric.

From the way of occurrence of calcite in a fibrous fabric it needs no argument that this fabric is a real formation in situ: it mostly occurs in voids; moreover the needles would not survive a transport of the soil material by drastic processes as e.g. transportation in a water-stream or dust storm (by erosion of the soil) and re-sedimentation elsewhere.

\section{Conclusion}

Accepting the philosophy of Brewer (1964) on soil materials, one arrives at the conclusion that $\mathrm{CaCO}_{3}$ in the soil must be considered plasma. This is because $\mathrm{CaCO}_{3}$ is a relatively soluble material which is capable of being or has been moved, reorganized, and/or concentrated by processes of soil formation.

Consequently, carbonate plasmic fabrics can be distinguished. Such fabrics are essentially spatial arrangements of like carbonate crystals in relation to each other (i.e. basic distribution patterns) in which the distance between individual crystals, and if necessary the orientation of these crystals in relation to each other, is considered. In this context carbonate crystals are considered like crystals if they are more or less of the same shape and size. Carbonate may form the following simple plasmic fabrics:

- Crystic: The distance between the (more or less isodiametric) crystals is small, or the crystals are contiguous throughout the soil material. When the crystals are small the fabric is named fine crystic; whereas when the crystals are large it is named coarse crystic. In fine crystic plasmic fabric the composing crystals are usually smaller than $20 \mu \mathrm{m}$. However, the boundary between fine and coarse crystic plasmic fabric is arbitrarily. It might be laid down at some $50 \mu \mathrm{m}$ for the size of the individual composing crystals.

- Calcic: The distance between the (more or less isodiametric) crystals is clearly larger than in crystic fabric. Nevertheless, the crystals occur rather closely assembled throughout the soil material. Usually the space between the crystals is occupied by plasma of a different kind which, however, may also contain a certain amount of finely dispersed carbonate.

- Fibrous: The crystals are needle-shaped and occur closely together.

In case the distance between large (usually euhedral or subhedral) crystals is considerable, these crystals are not considered being part of the plasma of the soil 
material in which they occur, but units of a different kind (i.e. intercalary crystals) set in this soil material. Particularly when between the large crystals carbonate is lacking.

The above-explained way of describing carbonate is understandable and moreover readily applicable. The philosophy on which these fabrics are based is slightly different from Brewer's concept on plasmic fabrics, especially with respect to the calcic fabric.

\section{Acknowledgments}

The International Soil Museum at Utrecht (Netherlands) is warmly acknowledged for making Soil Monolith SU 6 available for this study. The author gives thanks to $\mathrm{Mr}$ D. Creutzberg, M.Sc. for critically reading the manuscript.

\section{References}

Anonymous, 1967. Supplement to Soil Classification System, 7th approximation. Soil Survey Staff, SCS, USDA. US Government Printing Office, Washington, D.C., 207 pp.

Anonymous, 1970. Soil taxonomy: selected chapters of the unedited text. Soil Survey Staff, SCS, USDA. US Government Printing Office, Washington, D.C.

Bal, L., 1970. Morphological investigations in two moder-humus profiles and the role of the soil fauna in their genesis. Geoderma 4: 5-36.

Bal, L., 1973. Micromorphological analysis of soils. Soil Survey Papers No 6. Netherlands Soil Survey Institute, Wageningen, $174 \mathrm{pp}$. (Also issued as Doctoral Thesis and obtainable from the author.)

Bal, L., 1975. Carbonate in soil: A theoretical consideration on, and proposal for its fabric analysis. 2. Crystal tubes, intercalary crystals, K-fabric. Neth. J. agric. Sci. 23 (in press).

Blokhuis, W. A., Th. Pape \& S. Slager, 1968-1969. Morphology and distribution of pedogenic carbonate in some vertisols of the Sudan. Geoderma 2: 173-200.

Brewer, R., 1964. Fabric and mineral analysis of soils. Wiley, New York, $470 \mathrm{pp}$.

Buursink, J., 1971. Soils of Central Sudan. Soils Department, State University, Utrecht, the Netherlands, $249 \mathrm{pp}$.

Buursink, J. \& L. Bal, 1975. An inceptisol formed in calcareous loess on the 'Dast-i-Esan Top' plain in North Afghanistan (in press).

Fedoroff, N., 1972. The clay illuviation. In: S. A. Pieniazek, S. Kowalinski, J. Drozd \& S. Licznar (Ed.), Soil micromorphology. Proc. 3rd int. Work. Meet. Soil Micromorph. (Wroclaw, Poland, 22-28 September 1969): 195-207. Polska Akademia Nauk, Zeszyt 123, Panstwowe Wydawnictwo Naukowe, Warszawa.

Gile, L. H., F. F. Peterson \& R. B. Grossman, 1965. The K horizon: A master soil horizon of carbonate accumulation. Soil Sci. 99: 74-82.

Jongerius, A., 1970. Some morphological aspects of regrouping phenomena in Dutch soils. Geoderma 4: 311-331.

Kowalinski, S., L. J. Pons \& S. Slager, 1972. Micromorphological comparison of three soils derived from loess in different climatic regions. Geoderma 7: 141-158.

Kubiena, W. L., 1938. Micropedology. Collegiate Press, Ames, Iowa, 243 pp.

Mermut, A. \& Th. Pape, 1971. Micromorphology of two soils from Turkey, with special reference to in-situ formation of clay cutans. Geoderma 5: 271-281.

Mulders, M. A., 1969. The arid soils of the Balikh basin (Syria). Soils Department, State University, Utrecht, the Netherlands, $196 \mathrm{pp}$.

Parfenova, E. J. \& E. A. Yarilova, 1965. Mineralogical investigations in soil science. Israel Program for Scientific Translations, Jerusalem, $178 \mathrm{pp}$.

Sehgal, J. L. \& G. Stoops, 1972. Pedogenic calcite accumulation in arid and semi-arid regions 
CARBONATE IN SOIL. 1. CRYSTIC, CALCIC AND FIBROUS PLASMIC FABRIC

of the Indo-Gangetic alluvial plain of Erstwhile Punjab (India) - Their morphology and origin. Geoderma 8: 59-72.

Siderius, W., 1973. Soil transitions in Central East Botswana (Africa). Publication of the International Soil Museum, Utrecht - International Institute for Aerial Survey and Earth Sciences (ITC), Enschede, the Netherlands, $260 \mathrm{pp}$. 